\title{
Does titanium in ionic form display a tissue-specific distribution?
}

\author{
Magdalena Golasik • Pawel Wrobel • Magdalena Olbert • \\ Barbara Nowak · Mateusz Czyzycki · Tadeusz Librowski • \\ Marek Lankosz $\cdot$ Wojciech Piekoszewski
}

Received: 24 February 2016/Accepted: 30 March 2016/Published online: 4 April 2016

(C) The Author(s) 2016. This article is published with open access at Springerlink.com

\begin{abstract}
Most studies have focused on the biodistribution of titanium(IV) oxide as nanoparticles or crystals in organism. But several reports suggested that titanium is released from implant in ionic form. Therefore, gaining insight into toxicokinetics of $\mathrm{Ti}$ ions will give valuable information, which may be useful when assessing the health risks of long-term exposure to titanium alloy implants in patients. A micro synchrotron radiation-induced X-ray fluorescence $(\mu$-SRXRF) was utilized to investigate the titanium distribution in the liver, spleen and kidneys of rats following single intravenous or 30-days oral administration of metal (6 mg Ti/b.w.) in ionic form. Titanium was mainly retained in kidneys after both intravenous and oral dosing, and also its compartmentalization in this organ was observed. Titanium
\end{abstract}

M. Golasik · W. Piekoszewski ( $\square$ )

Department of Analytical Chemistry, Faculty of

Chemistry, Jagiellonian University in Krakow, Ingardena

3, Krakow 30-060, Poland

e-mail: wpiekosz@tlen.pl

P. Wrobel · M. Czyzycki - M. Lankosz

Faculty of Physics and Applied Computer Science, AGH

University of Science and Technology, al. Mickiewicza

30, Krakow 30-059, Poland

M. Olbert · T. Librowski

Department of Radioligands, Faculty of Pharmacy,

Medical College, Jagiellonian University in Krakow,

Medyczna 9, Krakow 30-688, Poland in the liver was non-uniformly distributed-metal accumulated in single aggregates, and some of them were also enriched in calcium. Correlation analysis showed that metal did not displace essential elements, and in liver titanium strongly correlated with calcium. Two-dimensional maps of $\mathrm{Ti}$ distribution show that the location of the element is characteristic for the route of administration and time of exposure. We demonstrated that $\mu$-SRXRF can provide information on the distribution of titanium in internal structures of whole organs, which helps in enhancing our understanding of the mechanism of ionic titanium accumulation in the body. This is significant due to the popularity of titanium implants and the potential release of metal ions from them to the organism. 
Keywords Titanium - Organ distribution - Rat tissues · Micro synchrotron radiation-induced X-ray fluorescence

\section{Introduction}

The ongoing ageing process of the population in many countries will lead to the growing demand for restoring the function of damaged organs and tissues (Holzapfel et al. 2013). Medical devices designed for such purposes can be made from a variety of biomaterials, but one of the most popular are Ti-based alloys (Geetha et al. 2009). Many studies reported that titanium implants undergo biodegradation in the body (Matusiewicz 2014; Cundy et al. 2015; MartínCameán et al. 2015). Metal ions and biomaterial debris are released into peri-implant tissues as a result of corrosion and after this they can be transported by blood [Ti(IV) ions bound to transferrin] to other biocompartments (tissues) (Soto-Alvaredo et al. 2014; Zierden and Valentine 2016). But some studies reported that metallic debris did not migrate deep into the tissue around implant (Guibert et al. 2006) or the leakage of $\mathrm{Ti}$ to adjacent bone and later to organism was limited (Passi et al. 2002).

Up till now, most studies have been focused on the biodistribution of titanium(IV) oxide as particles in organism (Geraets et al. 2014; Elgrabli et al. 2015). But, as Sarmiento-González et al. (2009) suggested, soluble $\mathrm{Ti}$ ions are the main degradation products of these metal implants. Moreover, metal in such form has shown higher toxicity to cell lines (human enterocytes and murine osteoblasts) than the nanoparticles at similar concentration (Soto-Alvaredo et al. 2014). The health effects of long-term exposure to ionic titanium are still not well-described.

One aspect of potential risk assessment attributed to this form of metal is to evaluate places of its accumulation on the level of organs and their internal structures. There are many imagining techniques that can be used for that purpose including scanning electron microscopy with X-ray microanalysis (SEM/ EDS) (Patri et al. 2009; Zhang et al. 2015), particleinduced X-ray emission spectroscopy (PIXIE) (Sugiyama et al. 2015) or laser ablation-inductively coupled plasma mass spectrometry (LA-ICPMS) (Davies et al. 2015). Another popular method that is used for the visualization of metals distribution in whole organs is X-ray fluorescence (XRF). It possesses many advantages such as nondestructiveness and simple preparation process (Ralle and Lutsenko 2009). An exciting X-ray beam can be produced either with an X-ray tube or with a synchrotron storage ring. Synchrotrons are a common choice for the investigation of biological samples where the elemental concentrations are very low. They offer very high intensities, which increases the sensitivity and decreases the detection limits, and good resolution (down to $1 \mu \mathrm{m}$ ) (Lobinski et al. 2006). In previous studies micro synchrotron radiation-induced X-ray fluorescence ( $\mu$-SRXRF) was used for in vivo investigation of distribution and accumulation of nano- $\mathrm{TiO}_{2}$ in lungs (Zhang et al. 2013, 2016), the olfactory bulb (Wang et al. 2007) and brain (Wang et al. 2008) of mice after intratracheal instillation. As far as we know, no study of Ti imaging in whole organs for the analysis of biodistribution of titanium in ionic form has yet been published.

In this study, we presented the first quantitative assessment of the spatial distribution of titanium in kidney, liver, and spleen collected from rats administered intravenously or orally with soluble salt of this metal. We utilized a $\mu$-SRXRF technique for bioimaging of titanium in whole organs with quantitative data. Additionally we evaluated whether Ti influences the distribution of other metals $(\mathrm{Ca}, \mathrm{Cu}, \mathrm{Fe}, \mathrm{K}, \mathrm{Zn})$.

\section{Materials and methods}

\section{Animal experiments}

The animal experiments were performed in accordance with Polish and European regulations, and were approved by the Ethical Committee of the Medical College, Jagiellonian University in Krakow (Decision No. 129/2014). The rats were provided by the Animal Breeding Farm of the Faculty of Pharmacy, the Medical College, Jagiellonian University in Krakow. Male Wistar rats (240-260 g) were housed under standard laboratory conditions with a natural daynight cycle, a temperature of $22{ }^{\circ} \mathrm{C}$, the humidity at $55 \pm 5 \%$, and with free access to food and water.

The animals were randomly divided into 4 groups. For acute studies a single dose (equivalent to $6 \mathrm{mg}$ $\mathrm{Ti} / \mathrm{kg}$ body weight) of a solution of titanium citrate 
(prepared by the procedure described by Deng et al. (2004) was administered intravenously (i.v.) to 6 rats, and they were then euthanized $30 \mathrm{~min}(\mathrm{n}=3)$ and $180 \min (n=3)$ after the injection. In the multiple dose studies a group of 3 rats was given a daily dose of $6 \mathrm{mg} \mathrm{Ti} / \mathrm{kg}$ body weight by gavage (p.o.) for 30 days. The control rats $(n=3)$ received water without titanium citrate.

At the indicated time points (acute studies) or $24 \mathrm{~h}$ after the last oral dose (chronic studies), the rats were deeply anesthetized with thiopental $(75 \mathrm{mg} / \mathrm{kg}$ b.w., intraperitoneal injection) and euthanized. Samples of liver, kidneys and spleen were collected and immediately frozen.

\section{Samples preparation}

For $\mu$-SRXRF measurements the samples were mounted on the cryotome head with Shandon Cryomatrix (Thermo Electron Corporation, Pittsburgh, USA), frozen to $-20{ }^{\circ} \mathrm{C}$, cut using a Cryotome FSE cryostat (Thermo Scientific, UK) into $25 \mu \mathrm{m}$ thick sections and mounted immediately onto a $4 \mu \mathrm{m}$ thick Ultralene foil (SPEX, CertiPrep, USA) stretched on a PMMA ring. Afterwards, the slices were freeze-dried at $-80{ }^{\circ} \mathrm{C}$ ( 3 days), $-30{ }^{\circ} \mathrm{C}$ ( 1 day) and $4{ }^{\circ} \mathrm{C}$ ( 1 day). Then they were stored in desiccators at room temperature.

\section{$\mu$-SRXRF analysis}

The imaging of the elemental distribution of elements in thin freeze-dried slices of organs was done with the use of a micro synchrotron radiation-induced X-ray fluorescence ( $\mu$-SRXRF) technique. The experiment was conducted at the FLUO bending-magnet beamline of the ANKA synchrotron laboratory at Karlsruhe Institute of Technology in Karlsruhe (Germany). All measurements were carried out at a standard $45^{\circ} / 45^{\circ}$ geometry. The primary beam of $10 \mathrm{keV}$ photons was shaped with the use of slits- the output beam size was $250 \mu \mathrm{m}(\mathrm{V}) \times 177 \mu \mathrm{m}(\mathrm{H})$. Secondary radiation from the sample was collected with a KETEK silicon drift detector with a $50 \mathrm{~mm}^{2}$ active area. The flux of the primary beam was monitored with the use of an ionisation chamber and then used for normalisation of the acquired data. Analysed samples were mounted on a motorised $X-Y-Z$ stage. The step size of the scan was the same in both directions and was equal to
$250 \mu \mathrm{m}$. The average scanning area varied from $85 \mathrm{~mm}^{2}$ for spleen to $210 \mathrm{~mm}^{2}$ for liver. The counting time per pixel varied from $2 \mathrm{~s}$ for spleen and kidney to $3 \mathrm{~s}$ for liver.

Data analysis

All spectra were processed in the batch mode of AXIL software from the QXAS package (Bernasconi et al. 1996).

The calibration of sensitivity of the spectrometer was done with the use of thin-film standards with certified mass deposit per unit area: multielemental (NIST SRM 1831) and single compound standards of $\mathrm{KI}, \mathrm{Cu}, \mathrm{Fe}, \mathrm{Ti}, \mathrm{Zn}$ (Micromatter, Canada). The calibration was done in order to recalculate the measured X-ray fluorescence intensity into mass deposits per unit area with the use of the external standard method. All tissue samples were treated as thin samples, which is justified for elements above chlorine for employed thickness of sections (Szczerbowska-Boruchowska et al. 2012).

The mass deposits per unit area were calculated with following formula:

$M_{d, x, y, i}=\frac{I_{x, y, i}}{I_{s t d, i}} M_{d, s t d, i}$

where $M_{d, x, y, i}$ is mass deposit per unit area of $i$-th element in a pixel with $x, y$ coordinates, $I_{x, y, i}$ is normalized X-ray fluorescence intensity if $i$-th element in a pixel with $x, y$ coordinates, $I_{s t d, i}$ is a X-ray fluorescence intensity if $i$-th element measured for standard sample and $M_{d, s t d, i}$ is certified mass deposit per unit area of standard sample.

The inter-element correlations were calculated on the basis of mass deposits per unit area, and prior to this operation all pixels outside the tissue were removed. A Pearson's correlation analysis was applied to this dataset. Because tissue samples were treated as thin samples, correlations with $\mathrm{Cl}$ and elements below it $(\mathrm{P}, \mathrm{S})$ were not taken into account.

\section{Results and discussion}

A total of 38 samples from twelve rats were analyzed. The organs of the control animals contained no titanium, which suggested that the rats were not exposed to metal from other sources. 
To begin with, three lobes of liver (median, left and right lateral) from a rat from the i.v. group (at $180 \mathrm{~min}$ ) were scanned to check if the titanium distribution was different in these parts of the organ. The obtained maps of metal, presented in Fig. 1, were similar and, as such, the median lobe was chosen for further analysis.

Figure 2 shows the $\mu$-SRXRF maps of thin sections prepared from the liver of rats receiving either repeated oral (Fig. 2a) or single intravenous (Fig. 2b, c) doses of titanium citrate. The groups consisted of three animals, but only one representative map from each one was chosen. The distribution of titanium in all liver samples is not even. The single points of $\mathrm{Ti}$ deposition are present, especially in the organ collected from animals following long-term exposure. This group was also characterized by the highest surface mass of $\mathrm{Ti}$, which indicates that metal probably accumulates gradually in the liver.

\section{A}

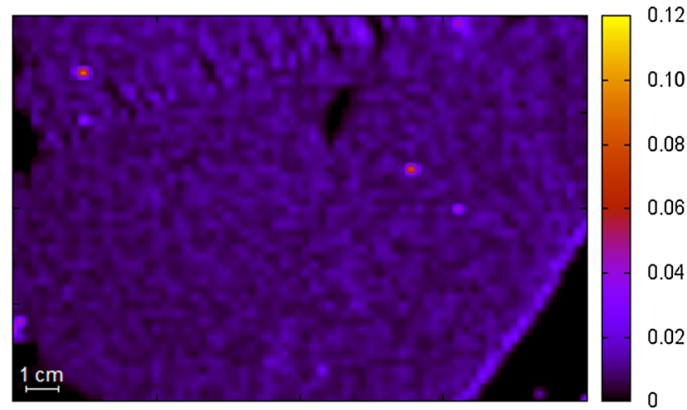

B
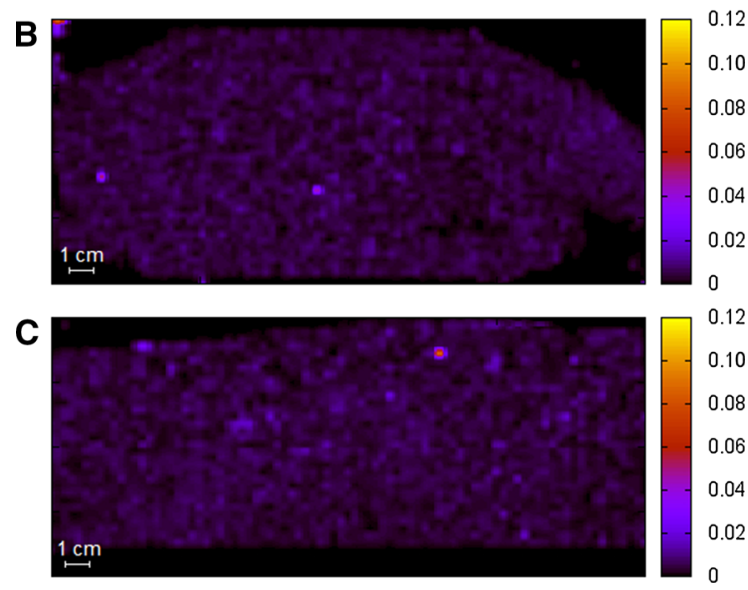

Fig. 1 Distribution of titanium in thin sections of median (a), left lateral (b) and right lateral (c) lobes of rat liver at $180 \mathrm{~min}$ after injection of single dose of titanium citrate. Data are presented in $\mu \mathrm{g} \mathrm{cm}^{-2}$
Pearson correlation study revealed a clear colocalization of $\mathrm{Ti}$ and $\mathrm{Ca}$ in livers of groups exposed to titanium. It was indicated by a statistically significant linear correlation (correlation coefficient between 0.48 and 0.80). Exemplary correlation matrix between elemental mass deposits per unit area in liver for the i.v. group (at $30 \mathrm{~min}$ ) is presented in Table 1. Such a trend was not observed in the organs of the control animals (mean correlation coefficient-0.25). Some areas of liver with the accumulation of titanium were also characterized by a high amount of calcium. We assume that an unknown titanium compound may have participated in the organ (especially after longterm exposure).

The distribution of $\mathrm{Ti}$ in kidneys, presented on Fig. 3, is even in the organs of animals after either p.o. (Figure 3a) or i.v. (Fig. 3b, c) dosing of soluble titanium citrate. Metal accumulates in the renal cortex as a result of repeated administration of $\mathrm{Ti}$, although maps obtained for both i.v. groups indicate that metal is quickly eliminated via the kidneys. After intravenous administration titanium is distinctly localized in the renal cortex (at $30 \mathrm{~min}$ ) and renal pelvis (at $180 \mathrm{~min})$.

The correlation analysis did not indicate the presence of a similar significant relationship between titanium and another element as in the case of liver. No linear correlation was observed between elements in any of groups.

Maps visualizing the biodistribution of titanium in the spleen (Fig. 4) show that titanium did not accumulate in large amounts in this organ after intravenous administration. On the other hand, the long-term oral exposure to titanium salt resulted in the deposition of metal in large areas of spleen (Fig. 4a).

The numerous strong correlations between titanium and other elements were observed in spleen samples from i.v. group at $180 \mathrm{~min}$ after $\mathrm{Ti}$ administration (Table 2). In another i.v. group titanium was positively correlated with $\mathrm{Ca}(\mathrm{r}=0.36)$. In the case of the spleens of animals exposed to long-term oral administration of metal salt there was only one correlation between $\mathrm{Ti}$ and $\mathrm{Fe}(\mathrm{r}=0.36)$.

On the basis of our results it can be concluded that $\mathrm{Ti}$ ions accumulate mainly in kidneys, and to some extent in the liver and spleen after intravenous administration. As was mentioned before, this is the first study presenting the bioimaging of ionic titanium at the organ level, and similar experiments were 


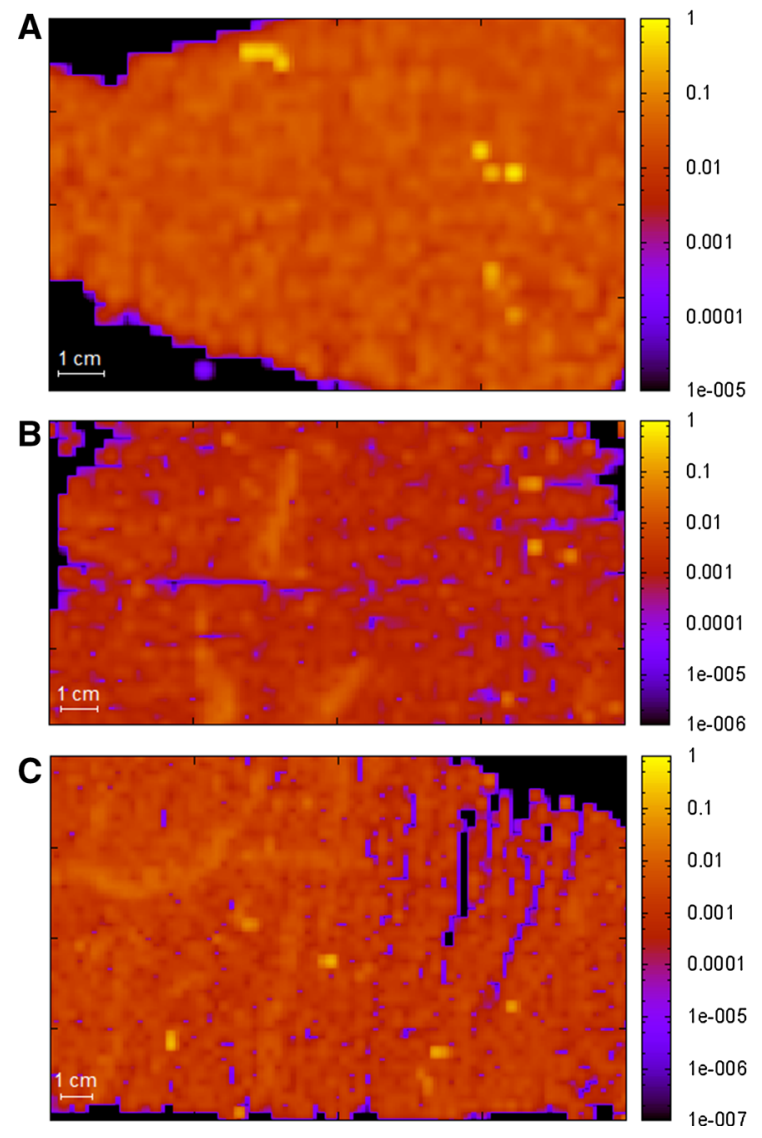

Fig. 2 Distribution of titanium in thin sections of liver collected from animals after 30-days oral exposure to Ti (a), at $30 \mathrm{~min} \mathrm{(b)} \mathrm{and} 180 \mathrm{~min}$ (c) after injection of single dose of titanium citrate. Data are presented in $\mu \mathrm{g} \mathrm{cm}^{-2}$ (log scale)

Table 1 Pearson's correlation matrix for mass deposits per unit area in the livers of rats at $30 \mathrm{~min}$ after intravenous administration of soluble Ti $(\mathrm{n}=3)$

\begin{tabular}{lrlllll}
\hline & $\mathrm{Ca}$ & $\mathrm{Cu}$ & $\mathrm{Fe}$ & $\mathrm{K}$ & $\mathrm{Ti}$ & $\mathrm{Zn}$ \\
\hline $\mathrm{Ca}$ & 1.00 & & & & & \\
$\mathrm{Cu}$ & -0.03 & 1.00 & & & & \\
$\mathrm{Fe}$ & 0.07 & 0.27 & 1.00 & & & \\
$\mathrm{~K}$ & 0.05 & $0.88^{\mathrm{a}}$ & 0.37 & 1.00 & & \\
$\mathrm{Ti}$ & $0.52^{\mathrm{a}}$ & 0.12 & 0.39 & 0.26 & 1.00 & \\
$\mathrm{Zn}$ & 0.09 & $0.47^{\mathrm{a}}$ & 0.21 & $0.43^{\mathrm{a}}$ & $0.41^{\mathrm{a}}$ & 1.00 \\
\hline
\end{tabular}

${ }^{a}$ Statistically significant correlation coefficient, $\mathrm{p}<0.05$

conducted only with titanium dioxide nanoparticles. For example, SEM/EDS technique was used to observe the agglomerates of nanoparticles in sections of liver, kidney, lung, heart, and spleen, collected from

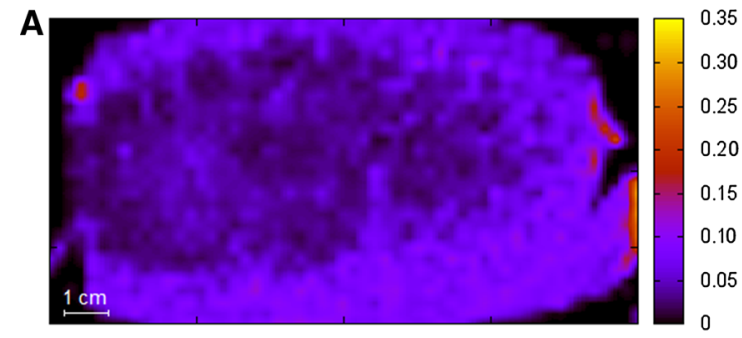

B

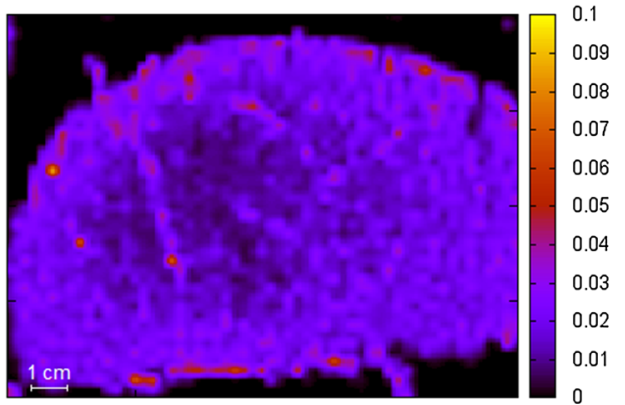

C

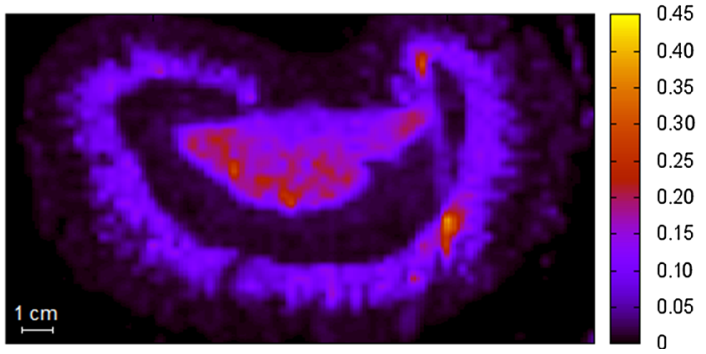

Fig. 3 Distribution of titanium in thin sections of kidney collected from animals after 30-days oral exposure to $\mathrm{Ti}$ (a), at $30 \mathrm{~min} \mathrm{(b)} \mathrm{and} 180 \mathrm{~min}$ (c) after injection of a single dose of titanium salt. Data are presented in $\mu \mathrm{g} \mathrm{cm}^{-2}$

mice after subcutaneous or intravenous injections of nano- $\mathrm{TiO}_{2}$ (Patri et al. 2009). However, only parts of organs were presented on elemental maps. Zhang et al. (2015) obtained quantitative maps of the distribution of $\mathrm{TiO}_{2}$ in lung collected from rats after intratracheal administration of nanoparticles, and observed the distinct differences in the pulmonary distribution of nano- $\mathrm{TiO}_{2}$ among the lobes of the lung.

Imagining techniques can also be applied in the studies of the corrosion of titanium implants. SRXRF technique was used to examine the migration of $\mathrm{Ti}$ ions to oral mucosa tissues close to the metal restoration (Sugiyama et al. 2015) and to the newly formed bone around the implant (Hoerth et al. 2014). Another studies on this topic utilized PIXE. Passi et al. (2002) characterized the deposits of Ti released from the dental implants to bone. They found that titanium mostly retained in the tissues around implant. Another 

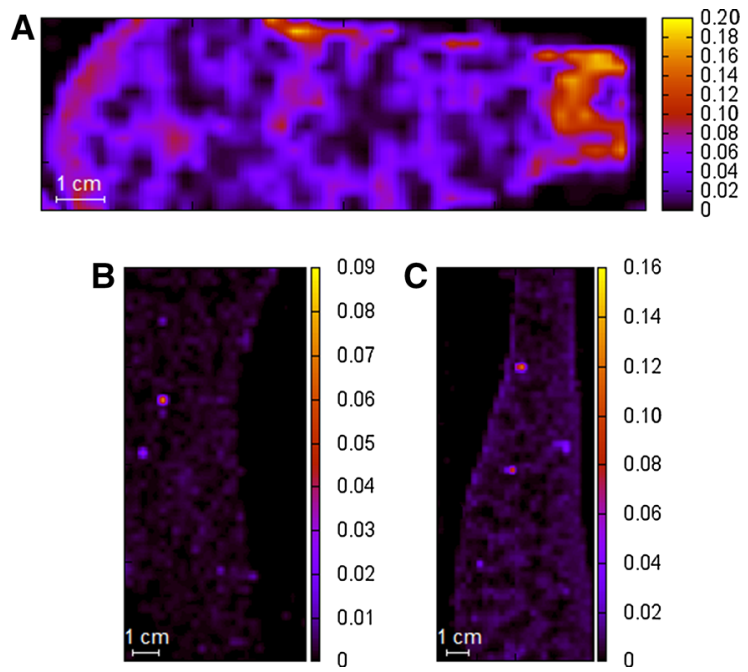

Fig. 4 Distribution of titanium in thin sections of spleen collected from animals after 30-days oral exposure to $\mathrm{Ti}$ (a), at $30 \mathrm{~min}$ (b) and $180 \mathrm{~min}$ (c) after injection of single dose of titanium salt. Data are presented in $\mu \mathrm{g} \mathrm{cm}^{-2}$

Table 2 Pearson's correlation matrix for mass deposits per unit area in the spleens of rats at $180 \mathrm{~min}$ after intravenous administration of soluble Ti $(n=3)$

\begin{tabular}{lrlllll}
\hline & $\mathrm{Ca}$ & $\mathrm{Cu}$ & $\mathrm{Fe}$ & $\mathrm{K}$ & $\mathrm{Ti}$ & $\mathrm{Zn}$ \\
\hline $\mathrm{Ca}$ & 1.00 & & & & & \\
$\mathrm{Cu}$ & -0.04 & 1.00 & & & & \\
$\mathrm{Fe}$ & 0.03 & $0.64^{\mathrm{a}}$ & 1.00 & & & \\
$\mathrm{~K}$ & 0.04 & $0.54^{\mathrm{a}}$ & 0.20 & 1.00 & & \\
$\mathrm{Ti}$ & $0.43^{\mathrm{a}}$ & $0.49^{\mathrm{a}}$ & $0.50^{\mathrm{a}}$ & $0.41^{\mathrm{a}}$ & 1.00 & \\
$\mathrm{Zn}$ & 0.08 & $0.51^{\mathrm{a}}$ & 0.11 & $0.92^{\mathrm{a}}$ & 0.40 & 1.00 \\
\hline
\end{tabular}

${ }^{a}$ Statistically significant correlation coefficient, $\mathrm{p}<0.05$

study focused on the metallic elements from knee prosthesis that leaked into surrounding capsular tissue (Guibert et al. 2006). The debris of titanium implant penetrated the capsular tissue to a depth of about several thousand micrometers.

Due to the lack of information on the spatial distribution of $\mathrm{Ti}$ ions in organs, we compared our results with those from studies where the total metal content after digestion of the organs was examined. Umbreit et al. (2012) analysed the tissue distribution of nano- $\mathrm{TiO}_{2}$ in mice after the intravenous (56 or $560 \mathrm{mg} \mathrm{kg}^{-1}$ per mouse) injection. The mice were inspected at 2, 4, 12 and 26 weeks after administration. Over that time microgranulomas (clusters of macrophages and lymphocytes with agglomerated
$\mathrm{TiO}_{2}$ ) were observed in the main filtering organsliver, lungs and spleen. The liver plays a key role in accounting for the rapid accumulation of $\mathrm{TiO}_{2}$ particles after exposure via the intravenous route (Xie et al. 2011). Another study (Cho et al. 2013) demonstrated the low bioavailability of titanium in the form of orally administered $\mathrm{TiO}_{2}$ nanoparticles-its concentration in the liver, spleen, kidney, and brain of rats was not significantly different from results obtained for the control group. Our results indicated that soluble $\mathrm{Ti}$ is retained in organs after oral exposure. Overall, the distribution of the ionic form of metal seems to be different than those of titanium dioxide nanoparticles.

\section{Conclusions}

This study investigates the biodistribution of titanium in ionic form after single intravenous or 30-days intragastric administration of a low dose of soluble metal salt on an animal model. The liver was characterized by single points of $\mathrm{Ti}$ accumulation, where in several cases calcium was also present in high concentration. It is presumed that some kinds of Ti compound may participate in these parts of the liver. These observations require further investigation. In kidneys metal had different concentrations in major regions: the renal cortex and renal pelvis. In $i . v$. groups most of the titanium was localized in the renal cortex (at $30 \mathrm{~min}$ ) or renal pelvis (at $180 \mathrm{~min}$ ), while in the p.o. group metal accumulated in the renal cortex. In the case of the spleen, almost no accumulation was observed in i.v. groups, but after oral administration metal aggregates in several regions of the organ. Accumulation of Ti in kidney, liver and spleen was observed after long-term exposure which can simulate this situation in patients with titanium implants. The results of correlation analysis suggested that titanium did not replace other elements in tissues (only several positive correlations were found). The strong association between $\mathrm{Ti}$ and $\mathrm{Ca}$ observed in liver supports the earlier presumption about the formation of unknown chemical species.

The obtained results indicate that $\mu$-SRXRF can provide spatial distribution images to show regional deposition and accumulation of titanium in whole organs. One of the disadvantages of this technique is limited spatial resolution as well as limited range of detectable elements. It was found that ionic titanium 
displays a different distribution pattern to $\mathrm{TiO}_{2}$ nanoparticles. Our findings contribute to a first step toward the identification of potential target organs for titanium in ionic form, and could be useful during clinical examination of patients with titanium implants.

Acknowledgments The assistance of Dr. Rolf Simon at the FLUO beamline at ANKA is gratefully acknowledged. The ANKA Angströmquelle Karlsruhe is acknowledged for the provision of beamtime. The authors thank Ms. Kaja Drogosz for technical assistance. This research was financed by the Polish National Science Centre (NCN) research Project No. 2013/11/ N/NZ4/02114.

\section{Compliance with ethical standards}

\section{Conflict of interest None.}

Open Access This article is distributed under the terms of the Creative Commons Attribution 4.0 International License (http://creativecommons.org/licenses/by/4.0/), which permits unrestricted use, distribution, and reproduction in any medium, provided you give appropriate credit to the original author(s) and the source, provide a link to the Creative Commons license, and indicate if changes were made.

\section{References}

Bernasconi G, Tajani A, Kregsamer P (1996) Quantitative X-ray analysis system (QXAS) software

Cho W-S, Kang B-C, Lee JK et al (2013) Comparative absorption, distribution, and excretion of titanium dioxide and zinc oxide nanoparticles after repeated oral administration. Part Fibre Toxicol 10:9. doi:10.1186/1743-8977$10-9$

Cundy WJ, Mascarenhas AR, Antoniou G et al (2015) Local and systemic metal ion release occurs intraoperatively during correction and instrumented spinal fusion for scoliosis. J Child Orthop 9:39-43. doi:10.1007/s11832-015-0631-6

Davies KM, Hare DJ, Bohic S et al (2015) Comparative study of metal quantification in neurological tissue using laser ablation-inductively coupled plasma-mass spectrometry imaging and X-ray fluorescence microscopy. Anal Chem 87:6639-6645. doi:10.1021/acs.analchem.5b01454

Deng Y-F, Zhou Z-H, Wan H-L (2004) pH-dependent isolations and spectroscopic, structural, and thermal studies of titanium citrate complexes. Inorg Chem 43:6266-6673. doi:10.1021/ic0496018

Elgrabli D, Beaudouin R, Jbilou N et al (2015) Biodistribution and clearance of $\mathrm{TiO}_{2}$ nanoparticles in rats after intravenous injection. PLoS One 10:e0124490. doi:10.1371/ journal.pone. 0124490

Geetha M, Singh AK, Asokamani R, Gogia AK (2009) Ti based biomaterials, the ultimate choice for orthopaedic implants-a review. Prog Mater Sci 54:397-425. doi:10. 1016/j.pmatsci.2008.06.004
Geraets L, Oomen AG, Krystek P et al (2014) Tissue distribution and elimination after oral and intravenous administration of different titanium dioxide nanoparticles in rats. Part Fibre Toxicol 11:30. doi:10.1186/1743-8977-11-30

Guibert G, Irigaray JL, Moretto P et al (2006) Characterisation by PIXE-RBS of metallic contamination of tissues surrounding a metallic prosthesis on a knee. Nucl Instrum Methods Phys Res Sect B 251:246-256. doi:10.1016/j. nimb.2006.06.032

Hoerth R, Katunar M, Gomez Sanchez A et al (2014) A comparative study of zirconium and titanium implants in rat: osseointegration and bone material quality. J Mater Sci Mater Med 25:411-422. doi:10.1007/s10856-013-5074-3

Holzapfel BM, Reichert JC, Schantz J-T et al (2013) How smart do biomaterials need to be? a translational science and clinical point of view. Adv Drug Deliv Rev 65:581-603. doi:10.1016/j.addr.2012.07.009

Lobinski R, Moulin C, Ortega R (2006) Imaging and speciation of trace elements in biological environment. Biochimie 88:1591-1604. doi:10.1016/j.biochi.2006.10.003

Martín-Cameán A, Jos A, Puerto M et al (2015) In vivo determination of aluminum, cobalt, chromium, copper, nickel, titanium and vanadium in oral mucosa cells from orthodontic patients with mini-implants by Inductively coupled plasmamass spectrometry (ICP-MS). J Trace Elem Med Biol 32:13-20. doi:10.1016/j.jtemb.2015.05.001

Matusiewicz H (2014) Potential release of in vivo trace metals from metallic medical implants in the human body: from ions to nanoparticles-a systematic analytical review. Acta Biomater 10:2379-2403. doi:10.1016/j.actbio.2014.02.027

Passi P, Zadro A, Galassini S et al (2002) PIXE micro-beam mapping of metals in human peri-implant tissues. J Mater Sci Mater Med 13:1083-1089. doi:10.1023/A:1020309 108950

Patri A, Umbreit T, Zheng J et al (2009) Energy dispersive X-ray analysis of titanium dioxide nanoparticle distribution after intravenous and subcutaneous injection in mice. J Appl Toxicol 29:662-672. doi:10.1002/jat.1454

Ralle M, Lutsenko S (2009) Quantitative imaging of metals in tissues. Biometals 22:197-205. doi:10.1007/s10534-0089200-5

Sarmiento-González A, Encinar JR, Marchante-Gayón JM, Sanz-Medel A (2009) Titanium levels in the organs and blood of rats with a titanium implant, in the absence of wear, as determined by double-focusing ICP-MS. Anal Bioanal Chem 393:335-343. doi:10.1007/s00216-008-2449-2

Soto-Alvaredo J, Blanco E, Bettmer J et al (2014) Evaluation of the biological effect of $\mathrm{Ti}$ generated debris from metal implants: ions and nanoparticles. Metallomics 6: 1702-1708. doi:10.1039/C4MT00133H

Sugiyama T, Uo M, Wada T et al (2015) Estimation of trace metal elements in oral mucosa specimens by using SRXRF, PIXE, and XAFS. Biometals 28:11-20. doi:10.1007/ s10534-014-9796-6

Szczerbowska-Boruchowska M, Stegowski Z, Lankosz M et al (2012) A synchrotron radiation micro-X-ray absorption near edge structure study of sulfur speciation in human brain tumors-a methodological approach. J Anal At Spectrom 27:239-247. doi:10.1039/C2JA10211K

Umbreit TH, Francke-Carroll S, Weaver JL et al (2012) Tissue distribution and histopathological effects of titanium 
dioxide nanoparticles after intravenous or subcutaneous injection in mice. J Appl Toxicol 32:350-357. doi:10.1002/ jat. 1700

Wang JX, Chen CY, Yu HW et al (2007) Distribution of $\mathrm{TiO}_{2}$ particles in the olfactory bulb of mice after nasal inhalation using microbeam SRXRF mapping techniques. J Radioanal Nucl Chem 272:527-531. doi:10.1007/s10967-007-0617-z

Wang J, Chen C, Liu Y et al (2008) Potential neurological lesion after nasal instillation of $\mathrm{TiO}(2)$ nanoparticles in the anatase and rutile crystal phases. Toxicol Lett 183:72-80. doi:10.1016/j.toxlet.2008.10.001

Xie G, Wang C, Sun J, Zhong G (2011) Tissue distribution and excretion of intravenously administered titanium dioxide nanoparticles. Toxicol Lett 205:55-61. doi:10.1016/j. toxlet.2011.04.034

Zhang J, Li B, Zhang Y et al (2013) Synchrotron radiation X-ray fluorescence analysis of biodistribution and pulmonary toxicity of nanoscale titanium dioxide in mice. Analyst 138:6511-6516. doi:10.1039/C3AN01267K

Zhang G, Shinohara N, Kano H et al (2015) Quantitative evaluation of the pulmonary microdistribution of $\mathrm{TiO}_{2}$ nanoparticles using X-ray fluorescence microscopy after intratracheal administration with a microsprayer in rats. J Appl Toxicol 35:623-630. doi:10.1002/jat.3109

Zhang G, Shinohara N, Kano H et al (2016) Quantitative evaluation of local pulmonary distribution of $\mathrm{TiO}_{2}$ in rats following single or multiple intratracheal administrations of $\mathrm{TiO}_{2}$ nanoparticles using X-ray fluorescence microscopy. J Appl Toxicol. doi:10.1002/jat.3287

Zierden MR, Valentine AM (2016) Contemplating a role for titanium in organisms. Metallomics 8:9-16. doi:10.1039/ c5mt00231a 